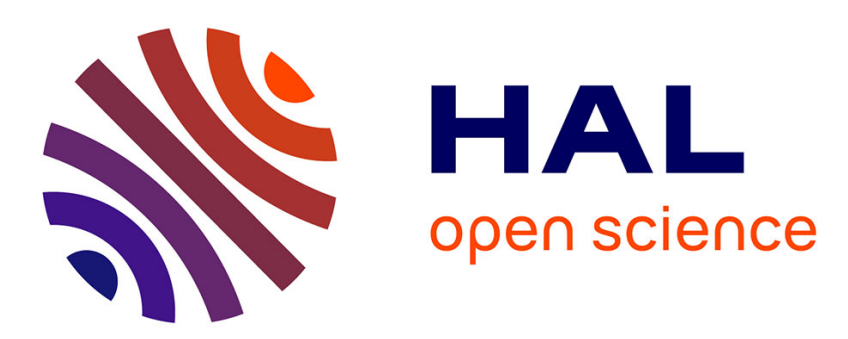

\title{
Identification of Complex Oxidation/Corrosion Behaviours of Boron Nitride Under High Temperature
}

Solenne Willemin, Paul Carminati, Sylvain Jacques, Jérôme Roger, Francis Rebillat

\section{- To cite this version:}

Solenne Willemin, Paul Carminati, Sylvain Jacques, Jérôme Roger, Francis Rebillat. Identification of Complex Oxidation/Corrosion Behaviours of Boron Nitride Under High Temperature. Oxidation of Metals, 2017, 88 (3-4), pp.247-256. 10.1007/s11085-017-9739-z . hal-02976932

\section{HAL Id: hal-02976932 \\ https://hal.science/hal-02976932}

Submitted on 23 Oct 2020

HAL is a multi-disciplinary open access archive for the deposit and dissemination of scientific research documents, whether they are published or not. The documents may come from teaching and research institutions in France or abroad, or from public or private research centers.
L'archive ouverte pluridisciplinaire HAL, est destinée au dépôt et à la diffusion de documents scientifiques de niveau recherche, publiés ou non, émanant des établissements d'enseignement et de recherche français ou étrangers, des laboratoires publics ou privés. 


\title{
Identification of complex oxidation/corrosion behaviours of boron nitride under high temperature
}

\author{
Solenne WILLEMIN, Paul CARMINATI, Sylvain JACQUES, Jérôme ROGER, Francis REBILLAT
}

LCTS UMR 5801, CNRS - University of Bordeaux, Safran, 3 allée de la Boétie, 33600 Pessac, FRANCE

\begin{abstract}
To characterize the oxidation/corrosion behaviour of boron nitride (BN) at high temperature and to determine kinetics, thermo-gravimetric analyses were performed on $\mathrm{BN}$ flat coatings under dry (80\% $\left.\mathrm{N}_{2}, 20 \% \mathrm{O}_{2}\right)$ and wet conditions $\left(10 \% \mathrm{H}_{2} \mathrm{O}, 70 \% \mathrm{~N}_{2}, 20 \% \mathrm{O}_{2}\right)$, at temperatures ranging from 700 to $900{ }^{\circ} \mathrm{C}$. The surface morphology was analysed by scanning electron microscopy. The aim of the study was to understand the complex behaviour of $\mathrm{BN}$ at high temperature under wet air. A model was then proposed to explain the recorded mass variations, by taking into account a competition between absorption and volatilization phenomena. Finally, an estimation of the amount of adsorbed species was extracted from these data.
\end{abstract}

\section{Keywords}

boron nitride; oxidation; thermo-gravimetric analysis; corrosion

\section{Introduction}

Ceramics and composites based on silicon carbide $(\mathrm{SiC})$ are interesting materials for structural components in high-temperature applications. Indeed, compared with metallic alloys historically used in the aeronautic industry, ceramic matrix composites (CMCs) are lighter (enabling a reduction in energy consumption) and stiffer. Their ability to resist to severe environmental conditions such as high temperatures and oxidizing/corrosive environments makes them key candidates for aeronautic industry. Boron nitride is a promising interphase material for SiC fibre-reinforced $\mathrm{SiC}$ matrix composites. Its layered structure allows matrix cracks deviation from mode I to mode II, protecting the fibres from premature failure. It has a better oxidation resistance than pyrocarbon used until now [1]. Furthermore, after oxidation, boron and its compounds give a $\mathrm{B}_{2} \mathrm{O}_{3}$ glassy phase with a low melting point of $450^{\circ} \mathrm{C}$. Boron nitride then turns out to be an efficient protective layer for fibres. However, this material is known to be very sensitive to moisture because boron oxide volatilizes, even at room temperature: when poorly crystallized, adsorption of moisture may occur in significant amount [2]. The aim of this study is to understand the complex behaviour of boron nitride at high temperature under wet air. 


\section{Experimental procedure}

\section{Sample Preparation}

Boron nitride coatings were prepared by chemical vapour deposition under chemical vapour deposition/chemical vapour infiltration (CVD/CVI) conditions (low pressure). In order to remove remaining partially decomposed reactive species trapped during the CVD deposition process, thermal post-treatments at high temperature were performed. The coatings were deposited on silicon carbide (SiC) rectangular substrates. For the studied coatings (Table 1 ), sample dimensions were approximately $5 \mathrm{~mm} \times 6 \mathrm{~mm}$, with an average mass of $180 \mathrm{mg}$ and a CVD boron nitride thickness of about $15 \mu \mathrm{m}$.

\section{Sample Characterization}

Thermo-gravimetric analyses (TGA) were performed using Setsys 1600 from Setaram. The specimens were placed in dry $\left(80 \mathrm{kPa} \mathrm{N}, 20 \mathrm{kPa} \mathrm{O}_{2}\right)$ and wet conditions $\left(10 \mathrm{kPa} \mathrm{H}_{2} \mathrm{O}, 70 \mathrm{kPa} \mathrm{N}, 20 \mathrm{kPa} \mathrm{O}\right.$ ), at temperatures ranging from 700 to $900{ }^{\circ} \mathrm{C}$. Dry air was generated by mixing $\mathrm{N}_{2}$ and $\mathrm{O}_{2}$. To obtain wet conditions, a dry gas mixture is saturated with water vapour by bubbling through a wash bottle, maintained in a thermally controlled bath. The temperature of the bath is fixed to a value corresponding to the required $\mathrm{P}_{\mathrm{H}_{2} \mathrm{O}(\mathrm{g})}$. In every performed test, $\mathrm{O}_{2}$ partial pressure was maintained constant to $20 \mathrm{kPa}$.

Elsewhere, surface morphology of oxidized coatings was characterized using scanning electron microscopy (SEM) FEI 400 FEG.

The crystallographic parameters of BN were characterized using X-ray diffraction (XRD, Bruker D8 Advance apparatus). The followed parameters were $d_{002}$ (shortest distance between two planes in the 002 orientation), $L_{c}$ (crystallite sizes, inversely proportional to the full width half maximum of the characteristic XRD peak) and the structural inhomogeneity (linked to the asymmetry of the XRD peak at the small angle side). Indeed, the coatings were made of a mixture of more or less crystallized BN (strong asymmetry of XRD peak). The crystallographic parameters of the studied deposits, before oxidation, are presented in Table 1. The factor "peak asymmetry" is calculated as the ratio between the right full width half maximum and the left full width half maximum for $2 \theta<2 \theta_{\text {average }}$ of the XRD peak. A value of 1 then indicates a symmetrical peak, i.e., a homogeneous coating.

\section{Results and discussion}

\section{Behaviour Under Dry Air}

In the absence of moisture, boron nitride oxidation occurs according to the following reaction:

$\mathrm{BN}+\frac{3}{4} \mathrm{O}_{2} \rightarrow \frac{1}{2} \mathrm{~B}_{3} \mathrm{O}_{2}+\frac{1}{2} \mathrm{~N}_{2}$

At temperatures below $1000{ }^{\circ} \mathrm{C}, \mathrm{B}_{2} \mathrm{O}_{3}$ volatilization is negligible because of its low saturated vapour pressure. Isothermal TGA analyses, therefore, only indicate a mass gain, induced by $\mathrm{B}_{2} \mathrm{O}_{3}$ formation on the flat coating surface. Oxidation kinetics follows a general relationship similar to the one described earlier by Deal and Grove [3] for the thermal oxidation of silicon. As long as the oxide thickness is thin, the relation describing the scale growth can be simplified by a linear law: oxidation kinetics is limited by reactions at the interface (limiting step). For longer duration, oxidation is later controlled by oxygen diffusion through the oxide thickness, and the kinetic rate follows a parabolic law. Two different oxidation rate constants can, therefore, be determined: the linear rate constant $k_{\mathrm{i}}$ and the parabolic rate constant $k_{\mathrm{p}}$. 
The TGA weight evolution of BN coatings aged at temperatures of 800,850 and $900{ }^{\circ} \mathrm{C}$ in dry conditions (Fig. 1) clearly follows the previous description. The values of rate constants extracted from experimental curves are gathered in Table 2. The weight evolution of the samples from TGA can be converted either to $\mathrm{BN}$ or $\mathrm{B}_{2} \mathrm{O}_{3}$ thickness evolution (consumption or formation, respectively). In this study, the linear rate constant $k_{\mathrm{i}}$ was determined from $\mathrm{BN}$ thickness evolution in function of time during the very first hours of the tests (linear evolution due to an interfacial regime). The parabolic rate constant $k_{\mathrm{p}}$ was determined by plotting the square of $\mathrm{B}_{2} \mathrm{O}_{3}$ thickness evolution in function of time (parabolic evolution due a regime limited by diffusion).

As expected, the oxidation kinetics is thermo-activated. Also, Arrhenius plots $(\ln (k)$ versus $1 / T)$ allows values of overall activation energies to be determined: 126 and $63.4 \mathrm{~kJ} / \mathrm{mol}$ for linear and parabolic regimes, respectively.

\section{Behaviour Under Wet Air}

In wet air, oxidation kinetics is significantly modified: as soon as small quantities of water vapour are introduced, volatilization of $\mathrm{B}_{2} \mathrm{O}_{3}$ can no more be neglected. Meschi et al. [4] have observed, using mass spectrometry, the presence of $\mathrm{H}_{3} \mathrm{BO}_{3}, \mathrm{HBO}_{2}$ and $\left(\mathrm{HBO}_{2}\right)_{3}$ gaseous species (for $\mathrm{T}$ ranging from about $800-1200{ }^{\circ} \mathrm{C}$ and $\mathrm{P}_{\mathrm{H}_{2} \mathrm{O}}$ ranging from 0.05 to $0.14 \mathrm{mmHg}$ ). From a thermodynamic approach of gas/ liquid equilibria, at temperatures above around $800-900{ }^{\circ} \mathrm{C}, \mathrm{HBO}_{2}$ is considered as the major species, whereas below this temperature the major species are mostly $\left(\mathrm{HBO}_{2}\right)_{3}$ and $\mathrm{H}_{3} \mathrm{BO}_{3}$. In wet air, a competition occurs between an oxide formation on the surface of the deposit, and its volatilization into $\mathrm{H}_{x} \mathrm{~B}_{\mathrm{y}} \mathrm{O}_{z}$ species $[5,6]$. This leads to a paralinear behaviour, which is a mixture of simultaneous parabolic and linear kinetics. It can be schematized as presented in Fig. 2. This theoretical model detailed by Tedmon [7] for $\mathrm{Cr}$ and Fe-Cr alloys and by Opila and Hann [8] for silicon carbide oxidation, has already been considered to describe the corrosion behaviour of CVD boron nitride [9].

Figure 3 shows the weight changes measured at temperatures of 700,750 and $800{ }^{\circ} \mathrm{C}$ in wet air $\left(10 \% \mathrm{H}_{2} \mathrm{O}\right)$ for $\mathrm{BN}$ coatings. As expected, recession of the boron nitride thickness and thus oxidation/corrosion kinetics increase with temperature. However, unlikely to the previously considered model [7], the curves exhibit: (1) a critical mass gain without the formation of an oxide scale and (2) two linear parts instead of only one during the stable recession step. A model explaining the differences between the observed and expected theoretical behaviours is developed below.

\section{Model for Wet Air}

As boron nitride is known to be moisture sensitive even at room temperature, a reasonable assumption explaining this behaviour would be an absorption process in the deposit under wet air. As shown in Fig. 3, and schematized in Fig. 4, a weight gain is clearly noticeable at the very beginning of oxidation while no oxide scale is formed over the surface (corresponding to stage 0 in Fig. 4). This could correspond to oxidizing/corrosive species absorption into BN coatings. Then, a continuous mass loss follows this weight gain. The mass loss shows two successive linear domains, corresponding to stages 1 and 2 in Fig. 4, respectively. The first linear regime is expected to result in the competition between the $\mathrm{OH}$ species progression in the boron nitride, and the volatilization of $\mathrm{H}_{x} \mathrm{~B}_{y} \mathrm{O}_{z}$ species. The second one indicates a faster mass loss. It can reasonably be assumed that: (1) the BN coating is saturated with $\mathrm{H}_{x} \mathrm{~B}_{\mathrm{y}} \mathrm{O}_{z}$ adsorbed species and (2) the contribution of the weight gain due to absorption of species is no longer present. Thus, this latter regime corresponds to the only volatilization of gaseous species until complete consumption of the coating: the resulting degradation process could be resumed as the active oxidation of hydrated BN molecules, "BNOH". This model seems to properly explain the differences encountered with the theoretical paralinear model. Such a kind of behaviour has already been observed for oxidation in air of poorly crystallized carbon (phenolic resin-based carbon): similar layered crystalline structure, sensitive to adsorption and/or intercalation phenomena $[10,11]$.

To highlight this assumed absorption phenomenon during an oxidation test, a reverse phenomenon of desorption is momentarily created through the introduction of a step under argon at the working 
temperature. Thus, oxidation tests were interrupted for a short period of time at constant temperature under neutral gas (argon), during the second linear regime (Fig. 5). After this modification of the "reactive" surrounding gas, a mass loss identified as desorption is clearly visible (once a correction of mass fluctuations is subtracted, due to the change in nature of gases). Moreover, when oxidizing gases (zone 3 in Fig. 5) is reintroduced, a mass gain due to absorption occurs again but at a lower level. The duration of the first linear regime is also reduced. This supports the hypothesis of absorption in the deposit: as BN coating becomes thinner, the volume of the sample that can be hydrated is lower.

The chemical reactions involved during the two linear domains are shown in Fig. 6 . The differences between the two linear rates are mainly due to the degree of absorption: (1) progression and (2) saturation. It can be assumed that the same molecular amount of boron nitride is consumed during regime 1 and regime 2 : the $\mathrm{BN}$ consumption in $\mathrm{mol} / \mathrm{h}$ in domain $1\left(k_{\mathrm{BN} 1}\right)$ equals that in $\mathrm{mol} / \mathrm{h}$ in domain $2\left(k_{\mathrm{BN} 2}\right)$. The difference of slopes between both linear regimes is proportional to the difference of mass balances between both involved overall reactions. Thus, the difference of mass balance can directly be related to the average molecular mass of adsorbed species by one mole of BN.

In a first step, from the slope of the TGA curves, a mass consumption rate, $k_{1} \mathrm{in} \mathrm{mg} / \mathrm{h}$, is determined (Table 3 ). Then, a molecular consumption rate, $k_{\mathrm{BN} 1}$, which corresponds to the only $\mathrm{BN}$ consumption, is deduced. As the mass weight rate $k_{2}$ measured by TGA is proportional to $k_{\mathrm{BN} 1}$ and to $M_{\mathrm{BNOH}}$, it is then possible to extract the molecular mass of hydrated $\mathrm{BN}$ molecules, $\mathrm{BNH}_{\mathrm{x}} \mathrm{O}_{\mathrm{z}}$. This average quantity of absorbed species, $\mathrm{H}_{\mathrm{x}} \mathrm{O}_{2}$, is thus estimated, reported to one mole of $\mathrm{BN}$ (It has been checked that after desorption, the coating is only made of $\mathrm{BN}$; no premature removal of nitrogen occurs during an oxidation/corrosion test).

The gaseous hydroxides responsible for the volatilization of " $\mathrm{B}_{2} \mathrm{O}_{3}$ " in moisture environments $\left(\mathrm{H}_{3} \mathrm{BO}_{3}, \mathrm{HBO}_{2}\right.$ and $\left.\left(\mathrm{HBO}_{2}\right)_{3}\right)$ indicate that the absorption capability around a boron atom is expected to be important (several chemical bonds between $\mathrm{B}$ and $\mathrm{O}$ or $\mathrm{H}$ atoms in each specie). Further, the layered crystalline structure of this material favours the insertion of gaseous species in the structure. Consequently, the average calculated quantities of $\mathrm{H}_{\mathrm{x}} \mathrm{O}_{2}$ absorbed species for one mole of $\mathrm{BN}$, from TGA data seem to be conceivable. A high capability of absorption could be expected around 800$900{ }^{\circ} \mathrm{C}$ in regard to the $\mathrm{H}_{\times} \mathrm{B}_{\mathrm{y}} \mathrm{O}_{2}$ gaseous species responsible to the volatilization of " $\mathrm{B}_{2} \mathrm{O}_{3}$ ", characterized by a higher $M_{\mathrm{H}_{\mathrm{x}} \mathrm{O}} / \mathrm{M}_{\mathrm{B}_{\mathrm{y}}}$ mass ratio $[5,6]$.

To highlight the phenomenon of hydrated species absorption in BN coatings, XPS analyses have been conducted on as-received and oxidized samples (quenched to keep their high-temperature state). The results, presented in Fig. 7, show that after an oxidation test, the amount of oxygen trapped inside the coating is larger than the initial quantity: close to the surface, the oxygen amount presents a maximum of 35 at.\%, which decreases to the stable value of 27 at.\% inside the deposit. Moreover, deconvolutions of B1s peaks indicate an initial B-O bonding percentage of 8 at.\%, which reaches 23 at.\% after oxidation. This clearly supports the presence of hydrated BN molecules inside the coating. Theses analyses will be further completed by Auger electron spectroscopy, in order to estimate the amount of oxygen across the whole thickness of the boron nitride coating.

SEM observations of BN surface morphologies after oxidation/corrosion have been carried out. As shown in Fig. 8, cracks are observed over poorly crystallized boron nitride coatings. This cracking is expected to occur during the desorption process, due to volume variation and/or to the elimination of trapped gases. From further experiments, a coating with a higher crystallization degree shows a lower weight gain due to an absorption/intercalation process and presents no cracking after testing, respectively. 


\section{Conclusions}

In this study, the oxidation/corrosion behaviour of CVD boron nitride flat coatings has been investigated. In wet air, no theoretical behaviour allows to describe accurately the oxidation/corrosion behaviour of BN coatings. Starting from a paralinear behaviour, a modelling is proposed by taking into account an absorption phenomenon of $\mathrm{H}_{x} \mathrm{O}_{2}$ species through the boron nitride thickness. The estimated quantities of absorbed species are consistent with the nature of $\mathrm{H}_{x} \mathrm{~B}_{y} \mathrm{O}_{z}$ hydroxides met at such level of temperatures in moist environments.

The next step in this work will be to identify the absorbed elements in the various expected reactions and to deduce the different kinds of chemical bonding involved between them deep inside $\mathrm{BN}$ deposits. By quenching the system during a corrosion test, it can be expected to keep trapped a major part of absorbed species. Then, the identification of these trapped species can be carried out by $\mathrm{X}$-ray photoelectron spectroscopy, Auger electron spectroscopy and glow discharge optical emission spectroscopy analyses. Another undertaken possibility is an in situ identification by mass spectrometry of gaseous species removed during the desorption step.

\section{Acknowledgements}

This work has been supported by Herakles, through a PhD grant given to S. Willemin.

\section{References}

[1] S. Le Gallet, F. Rebillat, A. Guette and R. Naslain, Oxidation Resistance of BN Coatings with Different Textures, in High Temperature Ceramic Matrix Composites, eds. W. Krenkel, R. Naslain, H. Schneider (Wiley-VCH, Weinheim, New York, 2001), p. 193.

[2] S. Le Gallet, F. Rebillat, A. Guette and R. Naslain, Oxidation Resistance of BN Coatings with Different Textures, in High Temperature Ceramic Matrix Composites, eds. W. Krenkel, R. Naslain, H. Schneider, (Wiley-VCH, Weinheim, New York, 2001), p. 187.

[3] B. E. Deal and A. S. Grove, Journal of Applied Physics 36, 1965 (3770).

[4] D. J. Meschi, W. A. Chupka and J. Berkowitz, The Journal of Chemical Physics 33, (2), 1960 (530).

[5] X. Martin, Doctoral Thesis, University of Bordeaux 1, 2749 (2003).

[6] S. Wery, Doctoral Thesis, University of Perpignan, 2008PERP1061 (2008).

[7] C. S. Tedmon, Journal of the Electrochemical Society. 113, 1966 (766).

[8] E. J. Opila and R. E. Hann, Journal of the American Ceramic Society 80, 1997 (197).

[9] N. S. Jacobson, S. Farmer, A. Moore and H. Sayir, Journal of the American Ceramic Society 82, 1999 (197).

[10] X. Bertran, G. Chollon, M-A. Dourges, F. Rebillat, J. Dentzer and R. Gadiou, publication for submission to Journal of the European Ceramic Society.

[11] X. Bertran, Doctoral Thesis, University of Bordeaux 1, 4922 (2013). 


\section{Tables}

\begin{tabular}{lc} 
Sample & BN \\
\hline$L_{c}(\mathrm{~nm})$ & $2.1( \pm 0.1)$ \\
$d_{002}(\mathrm{~nm})$ & $0.343( \pm 0.001)$ \\
Peak asymmetry factor & 0.6
\end{tabular}

Tab. 1 Crystallographic parameters of the studied CVD BN coating

\begin{tabular}{|c|c|c|}
\hline Oxidation temperature $\left({ }^{\circ} \mathrm{C}\right)$ & $k_{\mathrm{i}}\left(\mu \mathrm{m}_{\mathrm{BN}} / \mathrm{h}\right)$ & $k_{\mathrm{p}}\left(\mu \mathrm{m}_{\mathrm{B}_{2} \mathrm{O}_{3}}{ }^{2} / \mathrm{h}\right)$ \\
\hline 800 & 1.8 & 190 \\
\hline 850 & 3.5 & 224 \\
\hline 900 & 6.0 & 350 \\
\hline
\end{tabular}

Tab. 2 Rate constants for oxidation of boron nitride in dry air

\begin{tabular}{|c|c|c|c|c|c|}
\hline $\begin{array}{l}\text { Oxidation } \\
\text { temperature }\left({ }^{\circ} \mathrm{C}\right)\end{array}$ & $\begin{array}{c}k_{1} \\
\left(\mathrm{mg} \mathrm{h}^{-1} \mathrm{~cm}^{-2}\right)\end{array}$ & $\begin{array}{c}k_{2} \\
\left(\mathrm{mg} \mathrm{h}^{-1} \mathrm{~cm}^{-2}\right)\end{array}$ & $\begin{array}{c}k_{\mathrm{BN} 1} \\
\left(\mathrm{~mol}_{\mathrm{BN}} / \mathrm{h}\right)\end{array}$ & $\begin{array}{c}M_{\mathrm{BNOH}} \\
(\mathrm{g} / \mathrm{mol})\end{array}$ & $\begin{array}{c}M_{\mathrm{OH}} \\
\left(\mathrm{g} / \mathrm{mol}_{\mathrm{BN}}\right)\end{array}$ \\
\hline 700 & -0.37 & -0.99 & $-1.5 \times 10^{-5}$ & 66.2 & 41.4 \\
\hline 750 & -0.71 & -1.96 & $-2.9 \times 10^{-5}$ & 68.0 & 43.2 \\
\hline 800 & -1.30 & -2.89 & $-5.2 \times 10^{-5}$ & 55.2 & 30.3 \\
\hline
\end{tabular}

Tab. 3 Estimation of the amount of absorbed species in the BN coating 


\section{Figures}

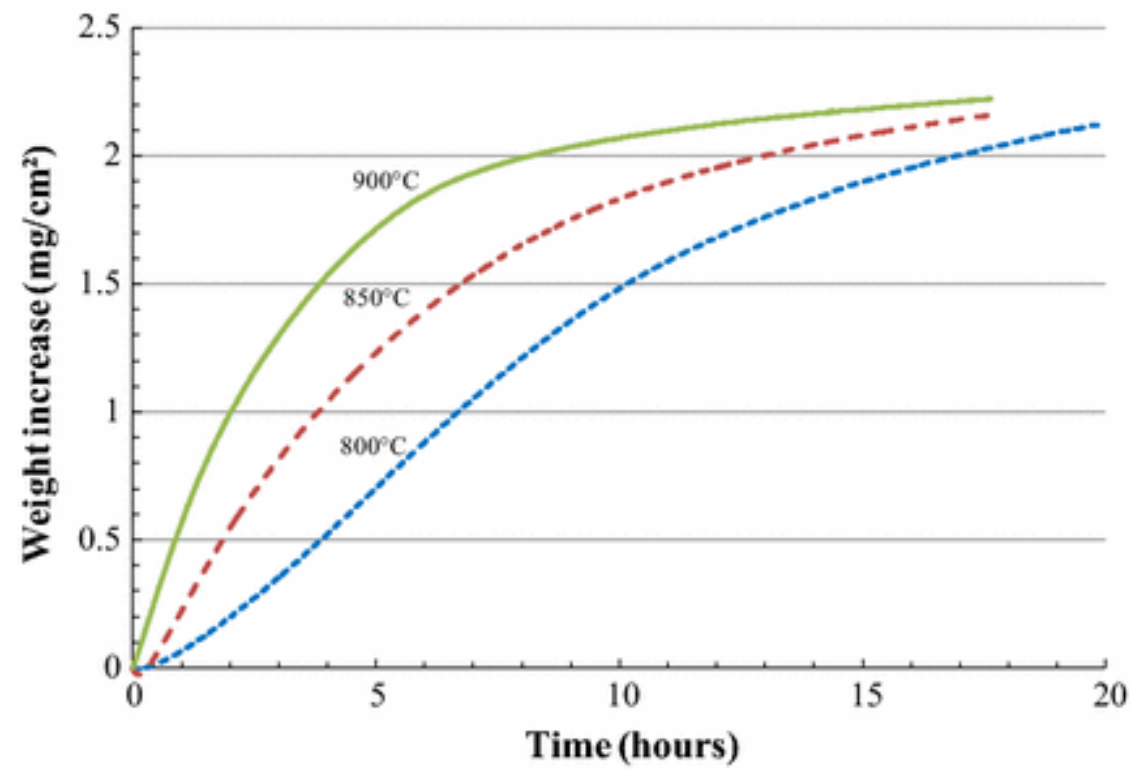

Fig. 1 Isothermal weight gain for BN in dry air at 800,850 and $900^{\circ} \mathrm{C}$ obtained from TGA experiments

\section{Oxide \\ thickness}

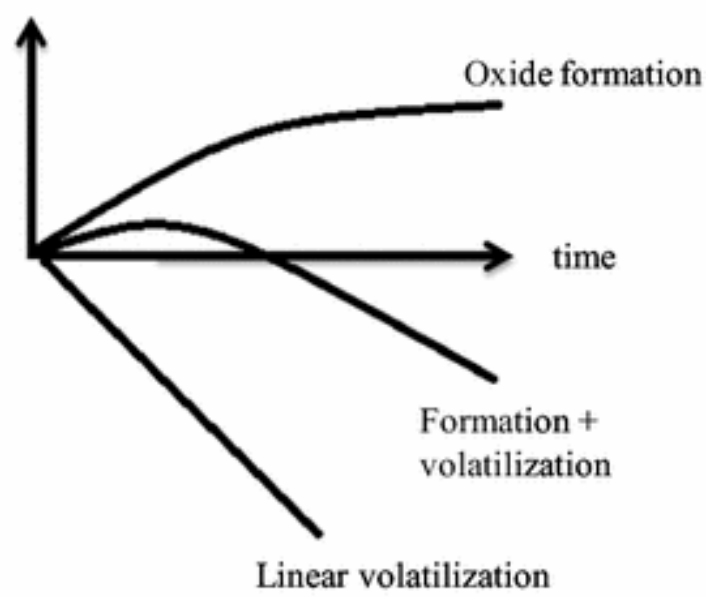

Fig. 2 Schematization of the paralinear behaviour model [7] 


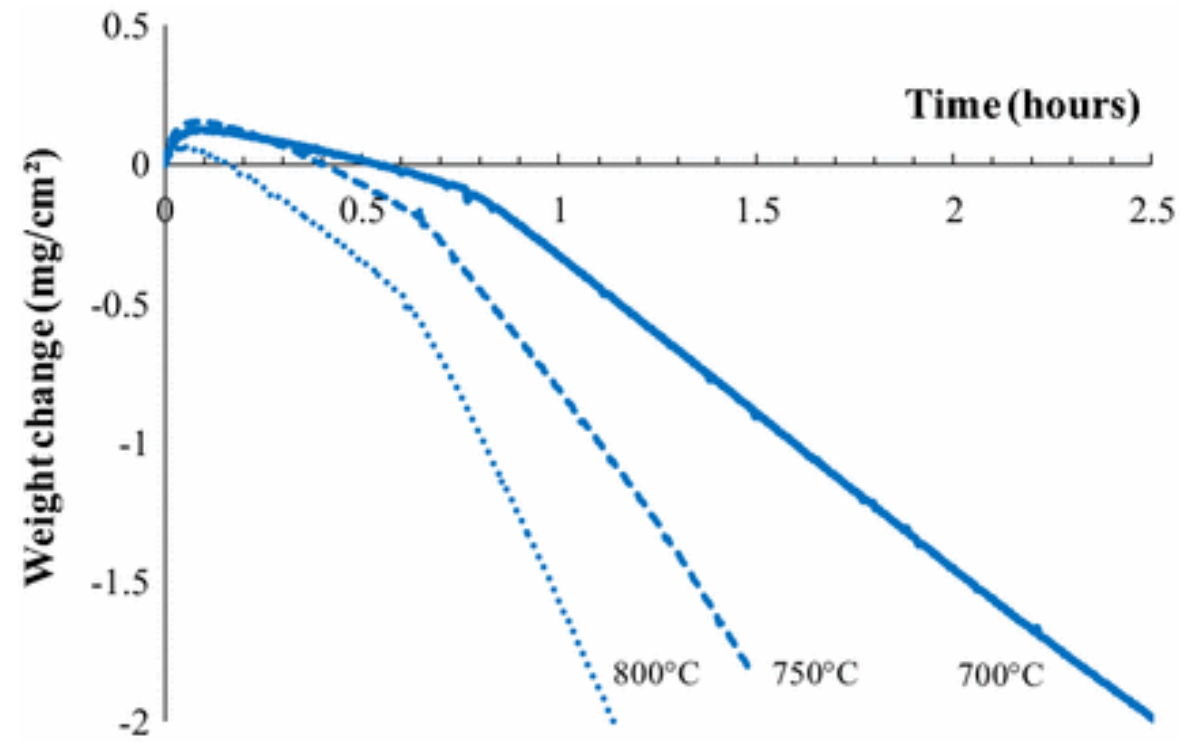

Fig. 3 Isothermal weight loss for $\mathrm{BN}$ in wet air $\left(10 \mathrm{kPa} \mathrm{H}_{2} \mathrm{O}\right)$ at 700,750 and $800{ }^{\circ} \mathrm{C}$

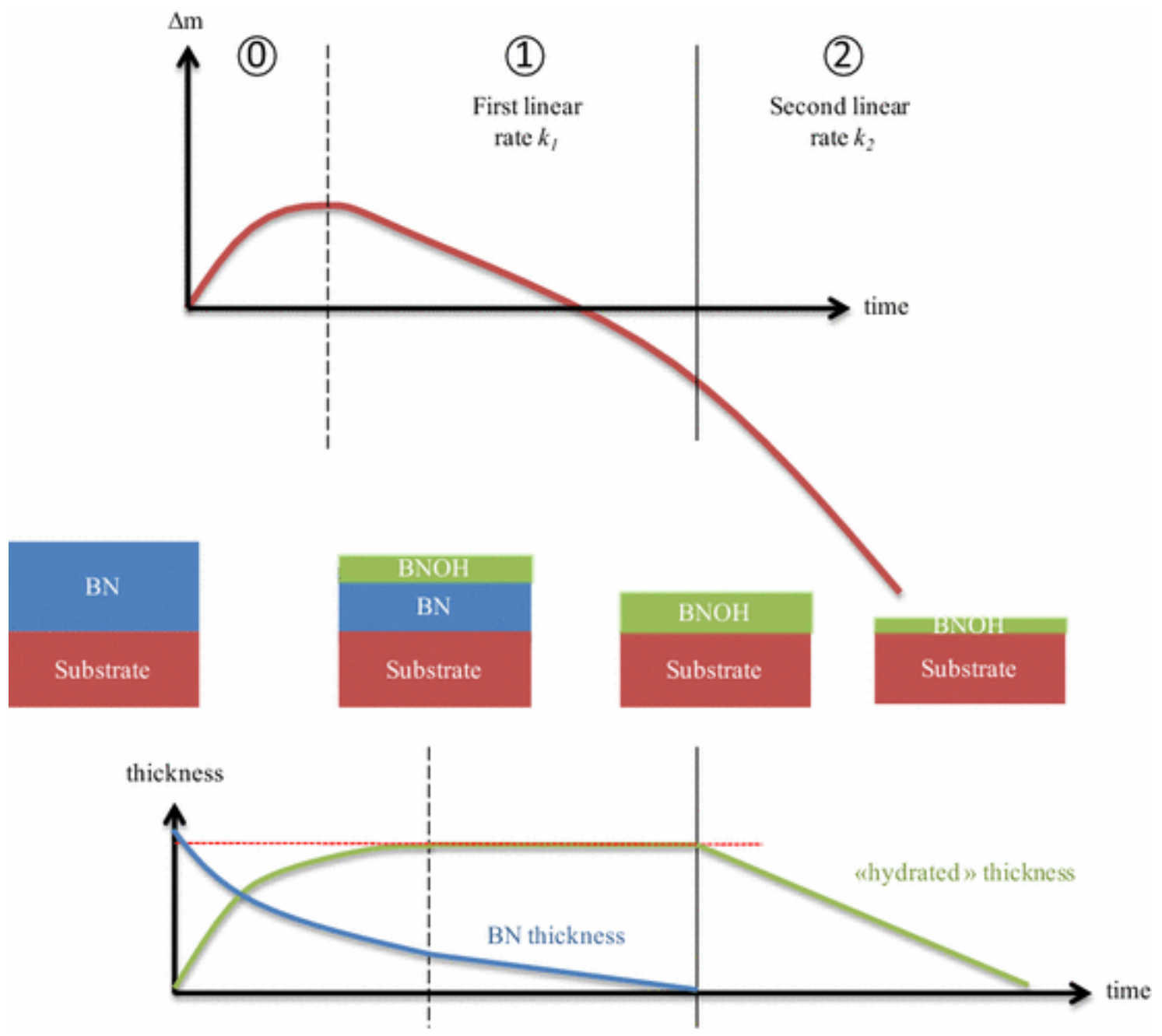

Fig. 4 Schematization of the oxidation behaviour of boron nitride in wet air: schematization of the evolution of the different thicknesses, in regard to mass variations, based on the absorption phenomenon 


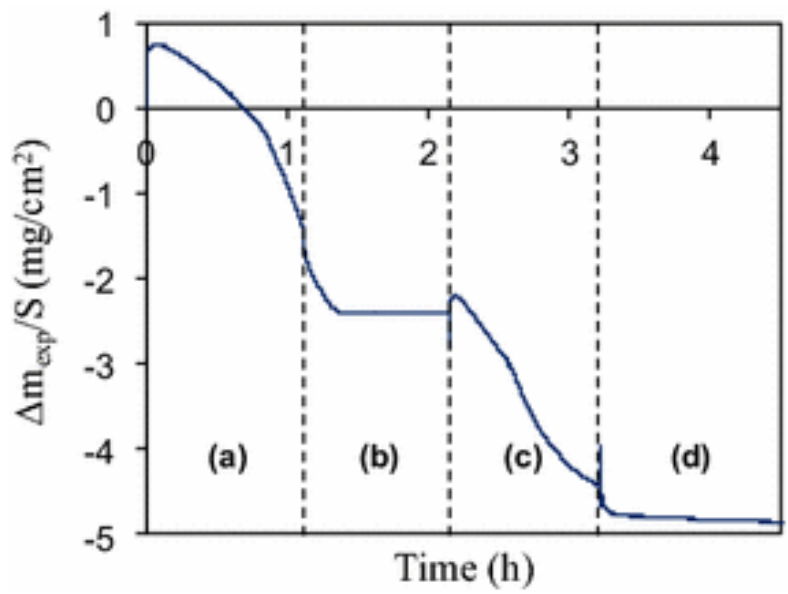

Fig. 5 Isothermal weight loss for $\mathrm{BN}$ at $800^{\circ} \mathrm{C}$ in wet air $\left(10 \mathrm{kPa} \mathrm{H}_{2} \mathrm{O}\right)$. During the oxidation tests $(1$ and 3$)$ two interruptions under inert gas ( 2 and 4 ) were introduced, at constant temperature

(1)

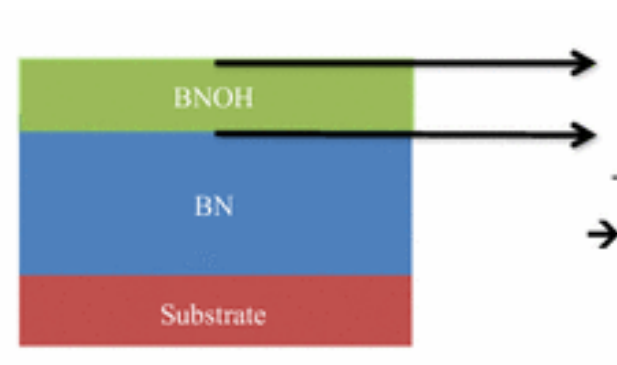

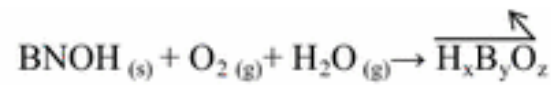

$\mathrm{BN}_{(\mathrm{s})}+\mathrm{O}_{2(\mathrm{~g})}+\mathrm{H}_{2} \mathrm{O}_{(\mathrm{g})} \rightarrow \mathrm{BNOH}_{(\mathrm{s})}$

$\rightarrow \mathrm{BN}_{(\mathrm{s})}+\mathrm{O}_{2(2)}+\mathrm{H}_{2} \mathrm{O}_{(\mathrm{g})} \rightarrow \mathrm{H}_{\mathrm{x}} \mathrm{B}_{y} \mathrm{O}_{z}$

(2)

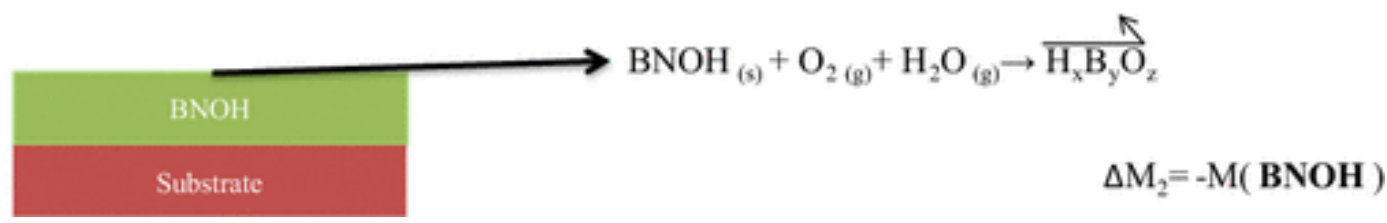

Fig. 6 Schematic of chemical reactions involved during the two linear domains, during the oxidation/corrosion of $\mathrm{BN}$ at high temperature (during exposure to wet air). Notations 1 and 2 correspond to the 1 and 2 linear stages presented in Fig. 4 
(a)

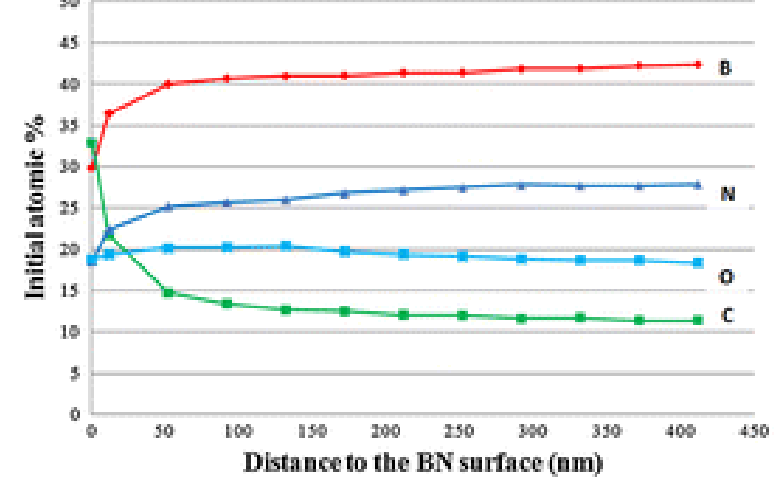

(b)

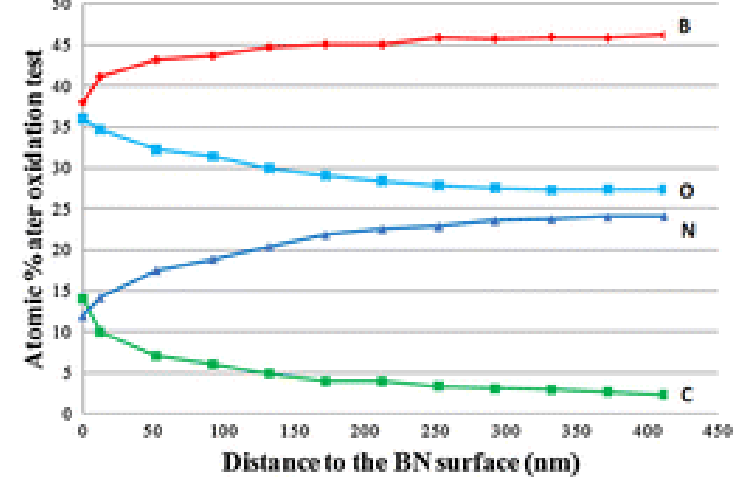

Fig. 7 XPS Analyses of (a) BN before wet air ( $10 \mathrm{kPa} \mathrm{H} 2 \mathrm{O} / 20 \mathrm{kPa} \mathrm{O} / 70 \mathrm{kPa} \mathrm{N}$ ) exposure and (b) BN after wet air $\left(10 \mathrm{kPa} \mathrm{H} \mathrm{H}_{2} \mathrm{O} 20 \mathrm{kPa} \mathrm{O}_{2} / 70 \mathrm{kPa} \mathrm{N}\right.$ ) exposure at $800{ }^{\circ} \mathrm{C}$
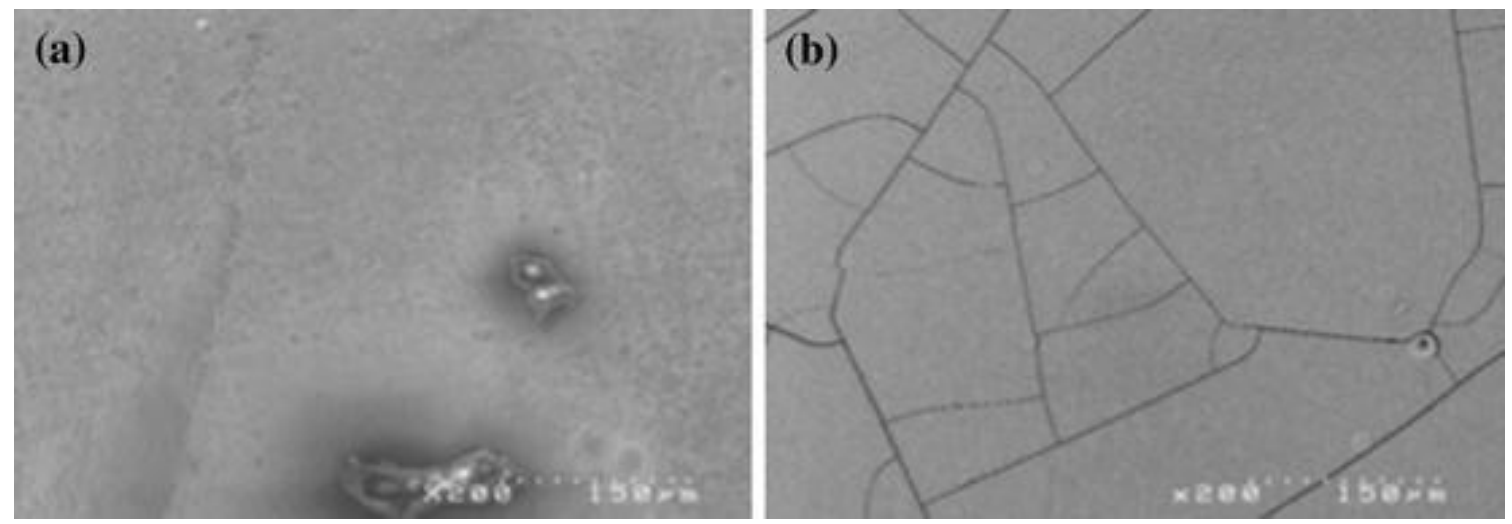

Fig. 8 SEM surface observation of (a) boron nitride coating before oxidation, (b) boron nitride coating after wet air exposure at $700{ }^{\circ} \mathrm{C}$. Cracks formation occurs during the desorption process 